\title{
The sheer stress of deciding when to replace the aorta in bicuspid valve disease
}

\author{
Mohamad Alkhouli, MD, J. Scott Rankin, MD, James D. Mills, MD, and Vinay Badhwar, MD
}

\author{
From the WVU Heart and Vascular Institute, West Virginia University, Morgantown, WVa. \\ Disclosures: Authors have nothing to disclose with regard to commercial support. \\ Received for publication Feb 21, 2017; accepted for publication March 3, 2017; available ahead of print April 1, \\ 2017. \\ Address for reprints: Vinay Badhwar, MD, Department of Cardiovascular \& Thoracic Surgery, West Virginia Uni- \\ versity, 1 Medical Center Drive, Morgantown, WV 26506-8059 (E-mail: vinay.badhwar@wvumedicine.org). \\ J Thorac Cardiovasc Surg 2017;153:1273-4 \\ 0022-5223/ $\$ 36.00$ \\ Copyright (C) 2017 by The American Association for Thoracic Surgery \\ http://dx.doi.org/10.1016/j.jtcvs.2017.03.018
}

In this issue of the Journal, Shan and co-authors ${ }^{1}$ provide us with a 4-dimensional (4D) flow magnetic resonance imaging (MRI) analysis of 15 normal trileaflet aortic valve controls compared with 50 age-matched patients with bicuspid aortic valve (BAV), right-left cusp fusion, mild aortic valve dysfunction, severe aortic insufficiency (AI), or severe aortic stenosis (AS). The focus of this study was to determine the impact of valve pathology on wall shear stress (WSS) in patients with BAV. The hypothesis was that MRI-derived metrics may establish noninvasive indicators to inform the risk stratification and treatment of these patients even when aortic size may be borderline.

Ascending aortic dilatation, aneurysm, and dissection comprise the heterogeneous expression of BAV aortopathy. ${ }^{2,3}$ The pathogenesis is complex. Two major causes have been proposed: (1) genetic: Although causative genes remain largely undetermined, familial clustering of BAV suggests a heritable cause ${ }^{4}$; (2) hemodynamic: There is sufficient evidence that cusp fusion in patients with BAV leads to abnormal aortic WSS in the ascending aorta, which stimulates vascular remodeling. 5,6

Contemporary advances in full-volume, flow-sensitive 4D MRI outlined in the current study ${ }^{1}$ permit detailed assessment of aortic blood flow patterns and quantification of WSS in the entire aorta. The principle findings of this study were as follows: (1) Peak WSS in patients with BAV occurs similarly in the right anterior aorta irrespective of aortic valve function; (2) patients with BAV without valve dysfunction have higher WSS compared with tricuspid aortic valve controls; and (3) BAV dysfunction (AI and AS) results in distinct but different hemodynamic effects in the ascending aorta. In patients with BAV, AI resulted in a universal WSS increase around the ascending aorta as a result of the increased cardiac output, whereas AS resulted in focal increase in WSS as a result of the exaggerated eccentricity of aortic outflow. These 2 distinct effects could have different long-term consequences in the affected aortic wall tissue; therefore, patients with BAV-related AS and AI might need to be approached differently. Thus, the configuration

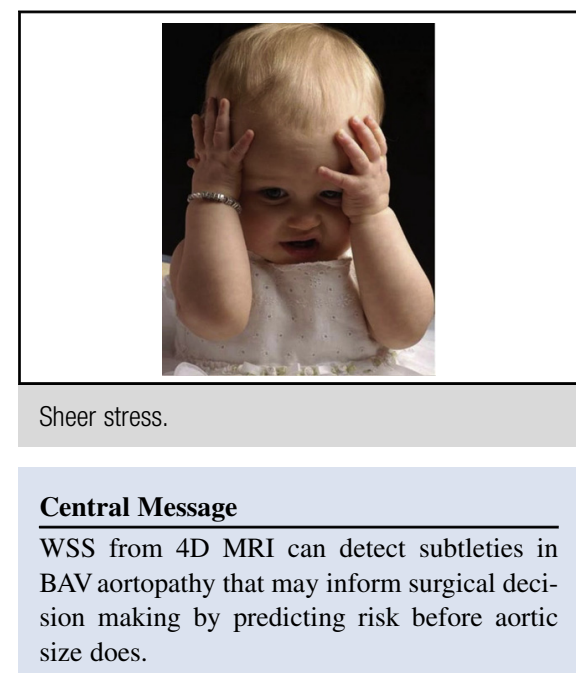

See Article page 1263.

of aortic valve leaflet repair or replacement could influence subsequent aortic outcomes. Although the surgical goal in both is smooth central laminar flow, 2-leaflet reconstructions for AI might emphasize achieving $180^{\circ}$ commissural geometry, whereas components of AS associated with 3 equal sinuses are better managed with trileaflet replacement.

Current guidelines on the timing of prophylactic aortic replacement in patients with BAV have mainly focused on the aortic size and the rate of aortic aneurysm expansion. ${ }^{8,9}$ However, Shan and co-authors ${ }^{1}$ add to the growing body of important work delineating that different BAV aortopathy phenotypes may be directly related to specific hemodynamic effects of valve pathology (AI vs AS). ${ }^{10}$

To translate these important findings from the bench to the bedside, future studies need to be designed to address the following issues: (1) identify WSS patterns that are associated with the highest risk of rapid aneurysmal dilatation and aortic dissection; (2) establish reference WSS values that can predict high-risk patients, in whom an intervention would be warranted even in the ascending aorta measures less than $5.5 \mathrm{~cm}$; (3) provide a simplified standard protocol for 4D MRI and possibly investigate whether a computed tomography angiography equivalent can be developed given the limited availability of 4D MRI in clinical practice; and (4) relate repair configuration to late aortic stability. 
The distinct hemodynamic effects of BAV pathology on the ascending aorta may soon add to the established anatomic criteria to facilitate more individualized patient risk stratification and surgical intervention in BAV aortopathy.

\section{References}

1. Shan Y, Li J, Wang Y, Wu B, Barker AJ, Markl M, et al. Aortic shear stress in bicuspid aortic valve patients with stenosis and insufficiency. J Thorac Cardiovasc Surg. 2017;153:1263-72.e1.

2. Opotowsky AR, Perlstein T, Landzberg MJ, Colan SD, O'Gara PT, Body SC, et al. A shifting approach to management of the thoracic aorta in bicuspid aortic valve. J Thorac Cardiovasc Surg. 2013;146:339-46.

3. Tadros TM, Klein MD, Shapira OM. Ascending aortic dilatation associated with bicuspid aortic valve: pathophysiology, molecular biology, and clinical implications. Circulation. 2009;119:880-90.

4. Cripe L, Andelfinger G, Martin LJ, Shooner K, Benson DW. Bicuspid aortic valve is heritable. J Am Coll Cardiol. 2004;44:138-43.

5. Barker AJ, Markl M, Bürk J, Lorenz R, Bock J, Bauer S, et al. Bicuspid aortic valve is associated with altered wall shear stress in the ascending aorta. Circ Cardiovasc Imaging. 2012;5:457-66.
6. Stephens EH, Hope TA, Kari FA, Kvitting JP, Liang DH, Herfkens RJ, et al. Greater asymmetric wall shear stress in Sievers' type 1/LR compared with 0/LAT bicuspid aortic valves after valve-sparing aortic root replacement. J Thorac Cardiovasc Surg. 2015;150:59-68.

7. Mazzitelli D, Nöbauer C, Rankin JS, Vogt M, Lange R, Schreiber C. Complete aortic valve cusp replacement in the pediatric population using tissue-engineered bovine pericardium. Ann Thorac Surg. 2015;100: 1923-5.

8. Nishimura RA, Otto CM, Bonow RO, Carabello BA, Erwin JP III, Guyton RA, et al. 2014 AHA/ACC guideline for the management of patients with valvular heart disease: a report of the American College of Cardiology/American Heart Association Task Force on Practice Guidelines. J Thorac Cardiovasc Surg. 2014;148:e1-132.

9. Hiratzka LF, Creager MA, Isselbacher EM, Svensson LG, Nishimura RA, Bonow RO, et al. Surgery for aortic dilatation in patients with bicuspid aortic valves: a statement of clarification from the American College of Cardiology/ American Heart Association Task Force on Clinical Practice Guidelines. J Thorac Cardiovasc Surg. 2016;151:959-66.

10. Sievers HH, Stierle U, Mohamed SA, Hanke T, Richardt D, Schmidtke C, et al. Toward individualized management of the ascending aorta in bicuspid aortic valve surgery: the role of valve phenotype in 1362 patients. J Thorac Cardiovasc Surg. 2014;148:2072-80. 